\title{
EXPERIMENTAL INVESTIGATION OF STEPPED AEROFOIL USING PROPELLER TEST RIG
}

\author{
Arun Prakash $\mathbf{J}^{1}$, Sweta $\mathbf{S}$ Radhakrishnan ${ }^{2}$, Ramavijay $\mathbf{N}^{3}$, Vishnupriya $\mathbf{S}^{4}$ \\ ${ }^{1}$ Assistant Professor, Department of Aeronautical Engineering, Karpagam University, Tamil Nadu, India \\ ${ }^{2}$ Student, B.E.IV year, Department of Aeronautical Engineering, Karpagam University, Tamil Nadu, India \\ ${ }^{3}$ Student, B.E.IV year, Department of Aeronautical Engineering, Karpagam University, Tamil Nadu, India \\ ${ }^{4}$ Lecturer, Department of Aeronautical Engineering, Karpagam University, Tamil Nadu, India
}

\begin{abstract}
Studies have confirmed that trapped vortices on corrugated airfoils modify the effective wing shape, resulting in an increase in lift. The intense system of vortices trapped in the cavity forces the flow to reattach, thus preventing separation. The vortices thereby change the lift, drag and pitching moments depending on whether the step is introduced on the upper or lower edge of the airfoil. The paper focuses on carrying out performance test on stepped (Kline Fogleman) airfoils using the propeller test rig. Stepped airfoils have single or multiple steps along the length of the wing. The trapped vortex cavity is being used by stepped airfoil which enhances the flow field characteristics An airfoil of the NACA series was chosen for which a step was introduced at $50 \%$ of the airfoil thickness at mid chord position half way along its length. These airfoils are then used for the fabrication of propeller blades. They are then tested for various speeds and blade angles using the propeller test rig. With the increase in lift, the efficiency of the propeller is also increased. The results are compared and studied with the convectional airfoils. Future scope of the work will also be discussed.
\end{abstract}

Keywords: Stepped airfoil, trapped vortices, propeller test rig

\section{INTRODUCTION}

Primary task of an airfoil which constitutes the vital part of a wing is to generate lift ${ }^{[1]}$ Various methods of lift enhancement have been proposed over the years. Flow separation over the suction surface of the airfoil at high angle of attack leads to a considerable loss of lift. Maintaining attached flow is thus critical in lift generation. Control of flow separation is required for lift enhancement, improved pressure recovery, stall delay and diminution in the form drag.

Concept of stepped airfoils was introduced by Richard L.Kline and Floyd F.Fogleman in early 1960's. Their design had an objective of developing a superior airfoil with enhanced lift, drag and stability characteristics and compliance over a wide range of speeds. This is achieved by the generation of vertical flow that alters the flow field resulting in favorable effects. ${ }^{[2]}$

Concept of trapped vortex cavity is being used by stepped airfoils which enhances the flow field characteristics. The intense system of vortices trapped in the cavity forces the flow to reattach, thus preventing separation. ${ }^{[3]}$ Thevortices thereby change the lift, drag and pitching moments depending on whether the step is introduced on the upper or lower edge of the airfoil. Large changes in the pressure distributions are obtained due to flow developments along the chord and therefore in the overall lift and drag coefficients. ${ }^{[4]}$

In this paper the team focuses on carrying out performance test on stepped aerofoil by testing it for various speed and blade angle in a propeller test rig.

\section{SCOPE OF CURRENT WORK}

By performing the desired changes in the flow field parameters the goal of enhancing the aerodynamic performance can be achieved. In this paper this is achieved by introducing the concept of stepped aerofoil.

These airfoils are then used for the fabrication of propeller blades. With the increase in lift, the efficiency of the propeller is also increased. Thus apart from the usage in radio controlled foam models these airfoils can also be used in propeller blades.

\section{CONCEPT OF STEPPED AEROFOILS}

The Kline-Fogleman or KFairoils were designed around 50 years ago by Richard Kline \& Floyd Fogleman. It was then devised for paper planes. Design consists of single or multiple steps along the length of the wing. ${ }^{[5]}$ The trapped vortex cavity is being used by stepped airfoil which enhances the flow field characteristics like lift, drag and stability characteristics, thereby making them adaptable over a wide range of speed.

Aerodynamic studies on stepped airfoils were conducted for different configurations defined by the step lengths, depths, and the location of steps on airfoil chord. Experimental tests and numerical investigation with steps on NACA 0012 and 23012 airfoils showed that higher lift coefficients were obtained with lower surface step located at half-chord, extending till the trailing edge at all angles of attack ranging from 0 to $10 \mathrm{deg}$. Further, upper surface steps located at half- 
chord and extending till $62.5 \%$ chord generated higher L/D ratios when compared with unmodified NACA 0012 airfoil at incidence(s) around $10^{0} .{ }^{[6]}$

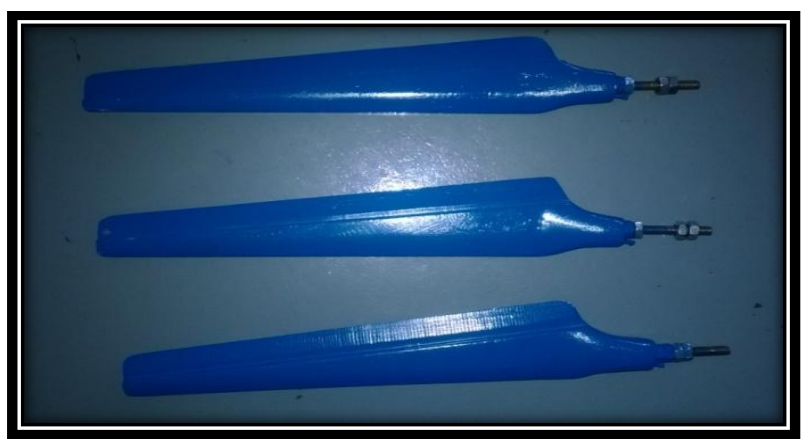

Fig -1: Fabricated stepped airfoils

\section{MOMENTUM THEORY}

Mathematical model of an ideal propeller or helicopter rotor can be described by The Momentum theory or Disk actuator theory by W.J.M.Rankine, Alfred George Greenhill and R.E. Froude. Here the rotor is assumed as an infinitely thin disc, which induces a constant velocity along the axis of rotation. ${ }^{[7]}$

Propellers generate positive as well as negative thrust. If it produces negative thrust it is said to operate in reverse. Compressibility effects must be considered when thrust is generated at high subsonic speed.

Propeller efficiency can be determined by obtaining the value of the useful power $\left(\mathrm{P}_{\text {actual }}\right)$. The power input is given by the product of thrust produced by the air pressure on the propeller disk and the air velocity through the disk.

$$
\begin{gathered}
\eta_{\mathrm{p}}=\frac{\text { Pactual }}{\text { Thrust }(\mathrm{T}) \times \text { Velocity }(\mathrm{V})}=\frac{\mathrm{T} \text { actual } \mathrm{x} \Delta \mathrm{v}}{\text { Thrust }(\mathrm{T}) \times \text { Velocity }(\mathrm{V})} \\
\eta_{\mathrm{p}}=\frac{\text { outputpower }}{T . V}
\end{gathered}
$$

The propeller efficiency is the ideal, free propeller efficiency. The actual efficiency will be lower because of energy losses due to non uniform flow, compressibility effects, slipstream rotation, blade profile drag and propeller block age due to a fuselage or a nacelle. It is desirable to keep the value of induced velocity (v) low for obtaining high value of propeller efficiency. It may be noted that, for a given amount of thrust, the induced velocity decreases with increase of flight speed. This momentum theory implies that higher efficiency is attainable as long as compressibility effects are negligible.

$$
\eta=\frac{T \text { actual } \times \Delta v}{0.7 \times \mathrm{Wm}} \text {, where } \mathrm{W}_{\mathrm{m}}=\text { Power drawn by motor. }
$$

\section{EXPERIMENTAL SET UP}

The performance characteristics of the propeller were obtained from a test rig. The fabricated stepped airfoil replaces the conventional airfoils of the test rig. The propeller was then tested for various speeds and blade angles. From the obtained values thrust will be calculate and finally its efficiency. Graphs were plotted to carry out the comparative study of the stepped airfoil and the ordinary airfoil which was initially installed in the test rig.

The equipment consists of an AC motor with drive to vary the speed. It is fixed on a load cell intern is connected to the thrust digital meter. The aerofoil designed to above system of three blades is mounted on a "L" frame chassis. Portable anemometer is supplied to measure the speed of the motor with electronic variac to control the speed. Wattmeter is provided to measure the motor power.

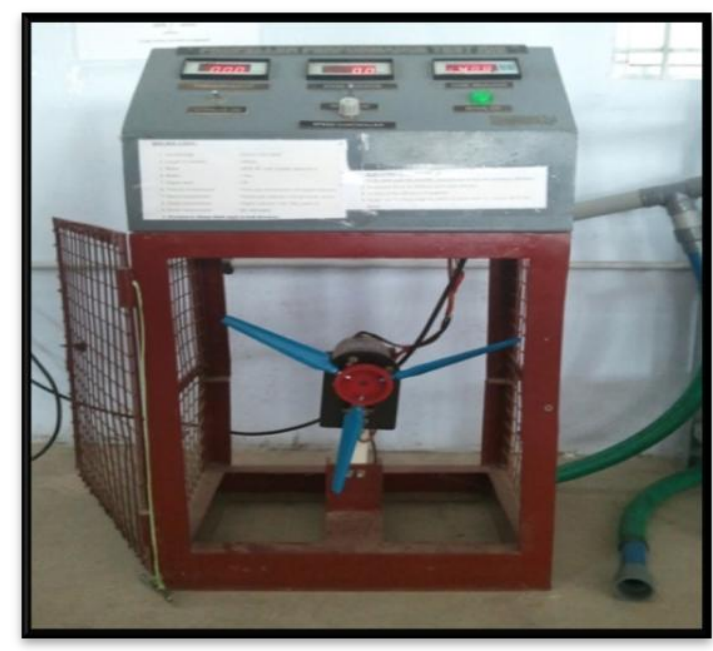

Fig-2: Test rig with stepped airfoils

\subsection{Momentum Theory Thrust is given by,}

$$
T=\frac{\pi}{4} D^{2}\left(\mathrm{v}+\frac{\Delta V}{2}\right) \rho \Delta \mathrm{v}
$$

$\mathrm{T}=$ Thrust in Newton $(\mathrm{N})$

$\mathrm{D}=$ Propeller diameter $(\mathrm{m})$

$\mathrm{V}=$ Velocity of incoming flow $(\mathrm{m} / \mathrm{s})$

$\Delta \mathrm{V}=$ addition velocity $(\mathrm{m} / \mathrm{s})$

$\rho=$ Density of $\operatorname{air}\left(\mathrm{kg} / \mathrm{m}^{3}\right)$

$\mathrm{T}_{\text {actual }}=$ measured by thrust meter in Newton $(\mathrm{N})$

Actual thrust power $=\mathrm{P}_{\text {actual }}=\mathrm{T}_{\text {actual }} \mathrm{x} \Delta \mathrm{v}$

\subsection{Power Supplied to the Propeller}

$$
\mathrm{P}_{\text {motor }}=0.7 \mathrm{x} \text { motor wattage }
$$

\subsection{Propeller Efficiency}

$$
\eta=\mathrm{P}_{\text {actual }} / \mathrm{P}_{\text {motor }}
$$

\section{PROCEDURE}

The blade angle is set to $0^{0}$ to $5^{0}(+/)$. The console is switched on. Check all the meters to show zero approximately. If not set them to zero values. Rotate the potentiometer pot is then rotated in the clockwise direction to bring the RPM to different speed. After stabilization the readings in thrust, power and RPM are noted in meters. After which, the air velocity of incoming flow and velocity behind the propeller are noted using anemometer (that is $\mathrm{V}$ and $\Delta \mathrm{V}$ ). The procedure is then repeated for various values of speeds. All 
the data's which are required for calculations can be obtained from the display of the test rig.

\section{TABLE OF READING}

The values of speed power and thrust, obtained from the experiment for both stepped as well as the conventional airfoils are shown in the table given below.

Table-1 Tabulated values of Speed, Power and Thrust for the conventional airfoil

\begin{tabular}{|l|l|l|l|}
\hline SI No: & $\begin{array}{l}\text { Speed } \\
(\text { RPM) }\end{array}$ & $\begin{array}{l}\text { Power } \\
\text { (Watts) }\end{array}$ & $\begin{array}{l}\text { Thrust } \\
\mathbf{T}_{\text {actual }}\end{array}$ \\
\hline 1 & 600 & 6 & -3.6 \\
\hline $\mathbf{2}$ & 800 & 15 & -0.49 \\
\hline $\mathbf{3}$ & 1000 & 25 & -0.68 \\
\hline $\mathbf{4}$ & 1200 & 31 & -1.03 \\
\hline $\mathbf{5}$ & 1500 & 34 & -1.28 \\
\hline
\end{tabular}

Table-2 Tabulated values of Speed, Power and Thrust for the stepped airfoil

\begin{tabular}{|l|l|l|l|}
\hline SI No: & $\begin{array}{l}\text { Speed } \\
(\text { RPM) }\end{array}$ & $\begin{array}{l}\text { Power } \\
\text { (Watts) }\end{array}$ & $\begin{array}{l}\text { Thrust } \\
\mathbf{T}_{\text {actual }}\end{array}$ \\
\hline 1 & 600 & 6 & -0.31 \\
\hline 2 & 800 & 11 & -0.56 \\
\hline 3 & 1000 & 17 & -0.86 \\
\hline 4 & 1200 & 26 & -1.17 \\
\hline 5 & 1500 & 45 & 0.96 \\
\hline
\end{tabular}

\section{CAlCulations}

\subsection{By the Momentum Theory of Thrust}

$$
\mathrm{T}=\frac{\pi}{4}(\mathrm{D})^{2}\left(\mathrm{~V}+\frac{\Delta v}{2}\right) \rho \Delta \mathrm{V}
$$

\subsection{For Conventional Airfoil}

$$
\mathrm{T}=\frac{\pi}{4}(0.4)^{2}\left(0.7+\frac{3.5}{2}\right) 1.1(3.5)
$$

$\mathrm{T}=1.184722 \mathrm{~N}$

Actual thrust power $=\mathrm{P}_{\text {actual }}=\mathrm{T}_{\text {actual }} \times \Delta \mathrm{v}$

$\mathrm{P}_{\text {actual }}=1.184722 \times 3.5$

$\mathrm{P}_{\text {actual }}=4.48$ watts

Power supplied to the propellerP $\mathrm{P}_{\text {motor }}=0.7 \mathrm{x}$ motor wattage $=$ $0.7 \times 34$

$\mathrm{P}_{\text {motor }}=23.8$ watts

Propeller Efficiency

$\eta=\mathrm{P}_{\text {actual }} / \mathrm{P}_{\text {motor }}$

$=\frac{4.48}{23.78} \times 100$

$\eta=18.82 \%$

The values of $\mathrm{v}, \Delta \mathrm{v}, \mathrm{T}_{\text {theoritical }}$ are then calculated and given below.

Table - 3 Calculated values of $v, \Delta v, T_{\text {theoritical }}$ for conventional airfoil

\begin{tabular}{|l|l|l|l|}
\hline Sl No: & $\mathbf{v}(\mathbf{m} / \mathbf{s})$ & $\Delta \mathbf{v}(\mathbf{m} / \mathbf{s})$ & $\mathbf{T}_{\text {theoritical }}$ \\
\hline
\end{tabular}

\begin{tabular}{|l|l|l|l|}
\hline 1 & 0.3 & 1.3 & 0.1706 \\
\hline 2 & 0.3 & 2.4 & 0.4973 \\
\hline 3 & 0.5 & 2.8 & 0.7350 \\
\hline 4 & 0.6 & 3.3 & 1.0258 \\
\hline 5 & 0.7 & 3.5 & 1.1847 \\
\hline
\end{tabular}

Table-4 Calculated Values Of $\mathrm{P}_{\text {actual }}, \mathrm{P}_{\text {motor }}$, Propeller Efficiency $(\eta)$ for conventional airfoil

\begin{tabular}{|l|l|l|l|}
\hline Sl no: & $\mathbf{P}_{\text {actual }}$ & $\mathbf{P}_{\text {motor }}$ & $\begin{array}{l}\text { Efficiency } \\
(\boldsymbol{\eta})\end{array}$ \\
\hline 1 & 0.468 & 4.2 & 11.14 \\
\hline 2 & 1.176 & 10.5 & 11.20 \\
\hline 3 & 1.904 & 17.5 & 10.88 \\
\hline 4 & 3.399 & 21.7 & 15.66 \\
\hline 5 & 4.48 & 23.8 & 18.82 \\
\hline
\end{tabular}

Similarly the calculations are repeated for stepped airfoils from the various values obtained.

\subsection{For Stepped Airfoil}

$$
\mathrm{T}=\frac{\pi}{4}(0.4)^{2}\left(2+\frac{5.8}{2}\right) 1.1(5.8)
$$

$\mathrm{T}=3.921 \mathrm{~N}$

Actual thrust power $=\mathrm{P}_{\text {actual }}=\mathrm{T}_{\text {actual }} \times \Delta \mathrm{v}$

$\mathrm{P}_{\text {actual }}=3.921 \times 5.8$

$\mathrm{P}_{\text {actual }}=31.5$ watts

Power supplied to the propeller,

$\mathrm{P}_{\text {motor }}=0.7 \times$ motor wattage $=0.7 \times 45$

$\mathrm{P}_{\text {motor }}=72.19$ watts

Propeller Efficiency

$\eta=\mathrm{P}_{\text {actual }} / \mathrm{P}_{\text {motor }}$

$=\frac{31.5}{72.19} \times 100$

$\eta=72.19 \%$

Based on the calculations carried out the maximum efficiency was found to be $72.19 \%$

Table- 5 Calculated values of v, $\Delta v, T_{\text {theoritical }}$ for stepped airfoil

\begin{tabular}{|l|l|l|l|}
\hline SI No: & $\mathbf{v}(\mathbf{m} / \mathbf{s})$ & $\Delta \mathbf{v}(\mathbf{m} / \mathbf{s})$ & $\mathbf{T}_{\text {theoritical }}$ \\
\hline 1 & 0.7 & 2.1 & 0.507 \\
\hline 2 & 1.4 & 2.8 & 1.0819 \\
\hline 3 & 1.4 & 3.7 & 1.659 \\
\hline 4 & 1.7 & 4.4 & 2.368 \\
\hline 5 & 2 & 5.8 & 3.921 \\
\hline
\end{tabular}

Table-6 Calculated Values Of $\mathrm{P}_{\text {actual }}, \mathrm{P}_{\text {motor }}$, Propeller Efficiency $(\eta)$ for stepped airfoil

\begin{tabular}{|l|l|l|l|}
\hline Sl no: & $\mathbf{P}_{\text {actual }}$ & $\mathbf{P}_{\text {motor }}$ & $\operatorname{Efficiency}(\boldsymbol{\eta})$ \\
\hline 1 & 1.064 & 4.2 & 25.33 \\
\hline 2 & 3.0293 & 7.7 & 39.34 \\
\hline 3 & 6.138 & 11.9 & 51.57 \\
\hline 4 & 10.4192 & 18.2 & 57.24 \\
\hline 5 & 22.7418 & 31.5 & 72.19 \\
\hline
\end{tabular}


Similarly these values were taken for various blade angles of which $+5^{0}$ gave the maximum efficiency. Based on the calculated values graphs were plotted for stepped as well as conventional airfoil. Comparative graph for +5 blade angle is shown below.

\subsection{Graph for Blade Angle $+5^{0}$}

Here it can be seen that stepped airfoils gave improved efficiency compared with conventional airfoil with its value increasing with the speed.

\subsection{Graph for Speed v/s Efficiency at Blade Angle $+5^{0}$}

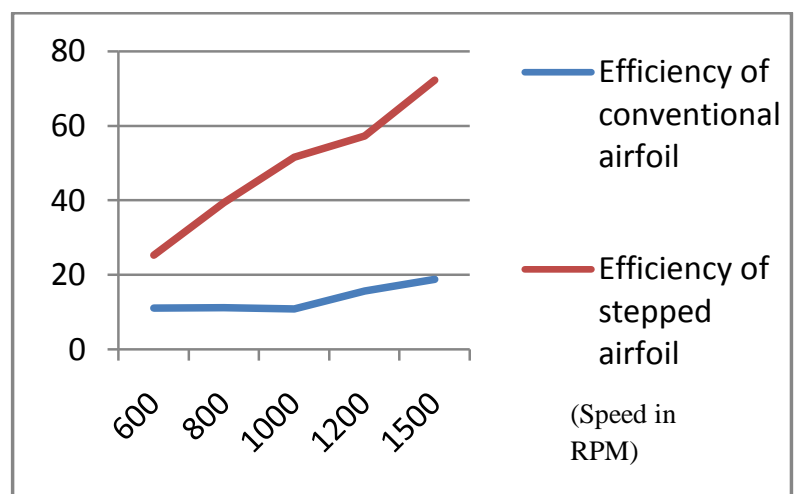

Chart 1 Comparison graph between stepped and conventional airfoil

When a blade angle of $+1^{0}$ was taken it can be seen that the efficiencies of stepped as well as conventional airfoils were increasing with the speed of the propeller.

For a blade angle of $+3^{0}$, that the efficiency of stepped airfoil and conventional airfoils coincides near 800 RPM later it drastically increases when compared to the efficiency of the conventional airfoil

For $-3^{0}$, the efficiency of stepped airfoil decreases and then increases as the speed of the propeller increases and gives a greater efficiency than the conventional airfoil.

When the values were plotted for stepped as well as conventional airfoil giving a blade angle of $-5^{0}$ it was observed that after 1000 RPM, the efficiency of stepped airfoil increases drastically whereas the conventional airfoil gives a very low value.

\section{RESULTS}

When the datas were compared, the propeller using stepped airfoil was found to give improved efficiency with a maximum value of $72.19 \%$

\section{CONCLUSIONS}

In this paper work, the experimental model is highlighted as a tool which is sufficiently powerful and useful to serve as a guide in the initial stages of study and preliminary design of aircraft propellers. The results showed that there is an improvement in the performance of the propeller when stepped airfoil replaced conventional airfoil. Future studies include applying the concept to the propellers of higher scale and RPM.

\section{REFERENCES}

[1]. Bertin, J. J. and Smith, M., Aerodynamics for Engineers, Prentice-Hall, 2nd edition.

[2]. Fertis, Demeter G., "New Airfoil Design Concept with Improved Aerodynamic Characteristics", Journal of Aerospace Engineering, Vol. 7, NO. 3, pp. 328-339, July, 1994.

[3]. Ringleb F.O., "Separation control by trapped vortices", In: Boundary Layer and Flow

Control", Ed. Lachmann G.V., Pergamon Press, Oxford, pp. 265-294, 1961.

[4]. Witherspoon, Stephen, and Finaish, Fathi, "Aerodynamic performance of an airfoil with step-induced vortex for lift augmentation", Journal of Aerospace Engineering, January 1998.

[5]. Kline, Richard, "The Ultimate Paper Airplane", Simon and Schuster, New York, NY, 1985.

[6]. Yeung W.W.H., "Lift Enhancement on Unconventional Airfoils", Jurnal Mekanikal, No. 22, 17-25, December 2006.

[7]. M. K. Rwigema,'Propeller Blade Element Momentum Theory with Vortex Wake Deflection"27th International Congress Of The Aeronautical Sciences

\section{BIOGRAPHIES}

Arun Prakash J, Assistant Professor, Department of Aeronautical Engineering, Karpagam University, Tamil Nadu, India.

Swetha S Radhakrishnan, Student, BE IV year, Department of Aeronautical Engineering, Karpagam University, Tamil Nadu, India.

Ramavijay N, Student, BE IV year, Department of Aeronautical Engineering, Karpagam University, Tamil Nadu, India.

Vishnupriya S, Lecturer, Department of Aeronautical Engineering, Karpagam University, Tamil Nadu, India. 